\title{
Vascular changes after cardiopulmonary bypass and ischemic cardiac arrest: roles of nitric oxide synthase and cyclooxygenase
}

\section{F.W. Sellke}

Division of Cardiothoracic Surgery, Department of Surgery, Beth Israel Deaconess Medical Center and Harvard M edical School, Boston, MA, USA

\section{Correspondence}

F.W. Sellke

Division of Cardiothoracic Surgery

Beth Israel Deaconess

Medical Center, Dana 905

330 Brookline Ave.

Boston, MA 02215

USA

Fax: + 1-617-667-4898

E-mail:

fsellke@ caregroup.harvard.edu

Presented at the Meeting "NO Brazil, Basic and Clinical Aspects of Nitric $O$ xide", Foz do Iguaçu, PR, Brazil,

March 10-13, 1999.

\section{Abstract}

Cardiac surgery involving ischemic arrest and extracorporeal circulation is often associated with alterations in vascular reactivity and permeability due to changes in the expression and activity of isoforms of nitric oxide synthase and cyclooxygenase. These inflammatory changes may manifest as systemic hypotension, coronary spasm or contraction, myocardial failure, and dysfunction of the lungs, gut, brain and other organs. In addition, endothelial dysfunction may increase the occurrence of late cardiac events such as graft thrombosis and myocardial infarction. These vascular changes may lead to increased mortality and morbidity and markedly lengthen the time of hospitalization and cost of cardiac surgery. Developing a better understanding of the vascular changes operating through nitric oxide synthase and cyclooxygenase may improve the care and help decrease the cost of cardiovascular operations.

\section{Introduction}

Received May 28, 1999 Accepted June 22, 1999
Refinements in methods of myocardial protection and operative techniques have improved the results of cardiovascular surgery. Yet, the operative treatment of cardiac diseases remains associated with systemic inflammation and a suboptimal outcome in many patients. These inflammatory changes are manifested by systemic hypotension, myocardial failure, increased vascular permeability and consequent dysfunction of organs such as the lungs, gut and brain. This is especially true when operations are performed on patients suffering acute myocardial ischemia, on patients in cardiogenic shock with

\section{Key words}

- Nitric oxide synthase

- Cyclooxygenase

- Heart surgery

- Endothelium

- Microcirculation reduced peripheral perfusion, or during prolonged extracorporeal perfusion. It has been estimated that 1 to $3 \%$ of patients suffer from coronary spasm and develop temporary ST segment elevations on EKG within hours of cardiovascular surgery (1-3). However, these patients generally suffer from atherosclerotic coronary vascular disease and have several other risk factors for endothelial dysfunction. Thus, these patients suffer from a baseline impairment of nitric oxide synthase (NOS). Equally important is the deterioration in cardiac function that frequently occurs within several hours of operation (4). Increased vascular permeability, impaired regulation of myocardial perfusion, and sys- 
temic inflammation undoubtedly play a major role in this negative response to surgery $(5,6)$.

The signs of altered vascular permeability and function are common after surgery in the coronary, pulmonary and other vascular beds. However, the mechanism has only recently been understood to be a consequence of numerous simultaneous pathological stimuli including activation of complement, activation and adherence of neutrophils, macrophages, and platelets, and increased oxidative stress. These pathologic processes are mediated in part by the increased release of nitric oxide (NO) due to expression of iNOS, and the release of other inflammatory substances such as thromboxane $\mathrm{A}_{2}$ as a consequence of expression of inducible cyclooxygenase (COX-2). These inflammatory mediators may potentially lead to changes in vasomotor regulation, endothelial integrity and vascular permeability that may compromise the recovery of patients undergoing cardiovascular surgery (6). This review briefly details the effects of ischemic cardioplegia under conditions of extracorporeal perfusion on the function and expression of NOS and COX.

\section{Cardioplegia and endothelial function}

\section{Effects on nitric oxide synthase}

It is well documented that hyperkalemia and ischemia-reperfusion alter endothelial structure and indices of endothelial function, most notably endothelium-dependent relaxation (7-10). After hyperkalemic arrest, endothelium-dependent relaxation is moderately impaired (7), possibly due to changes in membrane potential $(11,12)$, NOS substrate and cofactor depletion, alterations in concentration or compartmentalization of intracellular calcium $(13,14)$, or injury to the cell membranes and associated enzymes and ion pumps. In addition, the release of NO from the constitutive isoform of NOS (eNOS) is reduced after ischemia and cardioplegia, as determined by direct measurement (15). During the initiation of reperfusion after ischemic arrest, injury to the endothelium (and presumably eNOS) is observed and is due to increased oxidative stress caused by the generation of oxygen-derived free radicals (16), exposure of the endothelium to activated complement $(17,18)$, or the action of activated neutrophils and macrophages (6). When assessing eNOS activity by examining endothelium-dependent responses, uncertainty remains regarding whether the defect in enzyme function is due to an actual impairment in enzyme activity or to impaired signal transduction as a consequence of receptor or membrane injury. In addition, while impaired signal transduction and reduced agonist-stimulated production of NO likely contribute to the reduced endothelium-dependent relaxation after cardioplegia, increased degradation or binding of NO through interactions with free radicals may decrease the bioavailability of NO to the vascular smooth muscle (19).

\section{Causes of impaired endothelial function and vascular permeability}

Increased oxidative stress as a result of ischemia and/or reperfusion may produce direct and indirect injury to endothelial cells. The addition of either manganese superoxide dismutase or deferoxamine to a hyperkalemic cardioplegic solution markedly reduces the impairment of endothelium-dependent relaxation (20). This is presumably due to an inhibition of the generation of superoxide anion, the hydroxyl radical, and other free radicals. Furthermore, the interaction of superoxide anion and $\mathrm{NO}$ causes the formation of the peroxynitrite radical that has been implicated in mediating some of the free radical-induced injury. Whereas the expression of the constitutive isoform of NOS is generally not altered in vessels by brief 
$(<2 \mathrm{~h})$ crystalloid cardioplegia and reperfusion, expression of iNOS is increased (21). The increased release of NO due to expression of iNOS may not only contribute to the reduced activity of eNOS, but may also lead to reduced peripheral vascular resistance, increased vascular permeability (22), and other manifestations of systemic inflammation after cardiopulmonary bypass.

Abundant evidence supports a role for leukocytes in mediating much of the myocardial and systemic response to cardiovascular surgery. Leukocytes may contribute to much of the myocardial and endothelial damage after ischemia (23), hyperkalemic cardioplegia $(21,24)$, and cardiopulmonary bypass (CPB) (25). Indeed, focal leukocyteendothelial adherence has been observed on transmission electron microscopy following cardioplegia and reperfusion (7) and improved recovery of myocardial function and perfusion has been demonstrated when leukocyte-depleted blood has been used to reperfuse hearts after cardioplegic arrest (26). In addition, monoclonal antibodies to adhesion molecules (26) or chemotactic complement fragments (21) have beneficial effects on vascular recovery when administered prior to reperfusion. Activated leukocytes may cause endothelial dysfunction through the release of oxygen-derived free radicals, proteolytic enzymes, and inflammatory cytokines. Expression of P-selectin is initiated shortly after initiation of $\mathrm{CPB}$ or ischemia (27). This initiates the process of polymorphonuclear neutrophil (PMN) rolling, firm adherence and activation of PMN's. Subsequently, other adhesion molecules are upregulated, leading to the infiltration of PMN's into the perivascular tissues. PMN and macrophage infiltration has been documented in myocardium (28) after ischemia and cardioplegia and also in mesenteric (25) and pulmonary tissue (29) after CPB. Furthermore, increased circulating and tissue levels of tumor necrosis factor (TNF)-alpha, Il-6, Il-8, and other inflammatory cytokines liber- ated during and after CPB (30-33) have been directly associated with the increase in permeability of blood vessels $(6,30,31)$ and contribute to the inflammatory reaction and increased expression of inducible iNOS (34).

Another cytokine implicated in regulating vascular permeability is vascular endothelial growth factor (VEGF), also known as vascular permeability factor. VEGF is an extremely potent vasodilator, operating through the tyrosine kinase-regulated release of NO $(35,36)$. VEGF expression, as well as the expression of its flk-1 receptor, is increased after blood cardioplegia-reperfusion (35) or brief (15 min) unprotected warm ischemia (37). Interestingly, the microvascular relaxation response to exogenous VEGF is increased after blood cardioplegia, while that to another endothelium-dependent vasodilator, adenosine phosphate (ADP), is not changed (35). This suggests that a selective upregulation of functional VEGF receptors on the endothelium may contribute to increase vascular permeability and systemic inflammation.

The alternative complement pathway is activated during cardiovascular surgery, when blood interacts with components of the extracorporeal circuit (38). The classical complement cascade (39) may be activated during myocardial ischemia or cardioplegia and may affect the recovery of cardiac function during surgery. The anaphylotoxins $\mathrm{C} 3 \mathrm{a}$, $\mathrm{C} 4 \mathrm{a}$, and $\mathrm{C} 5 \mathrm{a}$ are released, which have been implicated in increasing neutrophil chemotaxis and adherence and in mediating some of the systemic inflammation associated with CPB $(25,38)$. In addition, most anaphylatoxins possess vasoactive properties of their own in addition to directly and indirectly affecting other mechanisms of vascular regulation. Thus, anaphylatoxins may cause vascular and myocardial injury and reduce myocardial perfusion. Some complement fragments such as C5b-9, the terminal membrane attack complex, may impair endothelial cell function by direct contact and mem- 
brane injury, in addition to increasing aggregation and chemotaxis of neutrophils (17). Exposure of isolated vessels to zymosaninduced complement-activated serum significantly reduces NO-mediated endothelium-dependent relaxation $(17,18,40)$, suggesting that activated complement directly causes endothelial injury even in microvessels isolated from other blood components and cellular elements. Complement activation may cause upregulation of adhesion molecules (17) and increased generation of oxygenderived free radicals (41). The administration of heparin (42) to anticoagulate patients prior to cannulation and systemic cooling (43) is probably protective against the effects of complement activation. However, the administration of protamine to reverse the effects of heparin is a potent activator of complement.

\section{Changes in activity and expression of cyclooxygenase}

Not only does cardioplegia-reperfusion lead to the impaired stimulated release of $\mathrm{NO}$, but it also induces the expression of the inducible isoform COX-2 that has been implicated in mediating much of the local and systemic inflammation in many disease states. Increased expression of COX-2 may cause an enhanced contractile response to serotonin of human atrial (44) or porcine ventricu$\operatorname{lar}(8)$ microvessels. This enhanced response is due to an increased production and release of contractile prostanoids since the response is inhibited in the presence of either indomethacin or NS398, a selective inhibitor of COX-2 (44). Subsequently, expression of COX-2 was documented to be increased in response to either ischemia or cardioplegia (44) which may affect both microvascular tone and permeability in part through the activation of tyrosine kinase receptors and mitogen-activated protein(MAP) kinase (45). In contrast to iNOS, which is not regulated by agonist stimulation or by intracellular calcium concentration, there is evidence that COX-2 is regulated by agonists such as serotonin (44). Prostaglandins (PG) are formed by the action of COX in a two-step conversion of arachidonic acid (46). First, the enzyme converts arachidonic acid to a cyclic endoperoxide $\left(\mathrm{PGG}_{2}\right)$ by the action of COX1 or COX-2, which is then followed by a peroxidase that cleaves the peroxide to yield endoperoxide $\left(\mathrm{PGH}_{2}\right)$. These unstable intermediate products of arachidonic acid metabolism by COX are then rapidly converted to the prostaglandins $\left(\mathrm{PGE}_{2}, \mathrm{PGF}_{2}\right.$, thromboxane $\mathrm{A}_{2}, \mathrm{PGI}_{2}$ ) by specific isomerase enzymes. The inducing factors leading to increased expression of COX-2 are most likely myocardial hypoxia and ischemia that occur during cardioplegic arrest and the exposure of myocardium and blood vessels to inflammatory cytokines. While COX-1 traditionally was thought to be expressed constitutively and COX-2 was felt to be inducible, it has recently been determined that COX-2 may be significantly expressed, or may be the predominant isoform, in the lungs of certain species, just as iNOS may be constitutively expressed (47) under basal conditions in the gut. It is difficult to separate the effects of NO and prostaglandin substances when discussing changes in the regulation of vasomotor activity and permeability during cardiovascular surgery, since they are often synergistic and complementary in their actions.

\section{Smooth muscle control of vascular tone}

The changes in the expression and activity of both NOS and COX may affect coronary and peripheral vasomotor tone during and after cardiac surgery. In addition to endothelial mechanisms, the regulation of coronary blood flow is determined by metabolic, autonomic, and myogenic mechanisms which are largely characteristics intrinsic to the vascular smooth muscle. Metabolic con- 
trol is mediated by the local release of vasoactive substances and increased probability of potassium channel opening (48), whereas myogenic mechanisms are based more on the intrinsic property of vascular smooth muscle to regulate vascular resistance in response to changes in transmural pressure. Experimentally, coronary microvascular myogenic contraction is preserved during extracorporeal circulation, but the pressurediameter relation is shifted upward, suggesting a decrease in vascular tone (49). Indeed, the upward shift in the pressure-diameter relation is normalized in the presence of $\mathrm{N}_{-}$ nitro-L-arginine, suggesting that much of this loss of tone is due to increased basal release of NO from iNOS. Furthermore, autonomic control and myogenic contraction of peripheral arterioles are impaired after CPB $(50,51)$. Alpha-adrenergic and protein kinase $\mathrm{C}$ (PKC)-mediated contraction in response to phorbol ester are impaired in skeletal muscle microvessels subjected to prolonged CPB (50). This probably accounts for much of the hypotension observed for several hours to days after extracorporeal circulation. As discussed above, the cause of this alteration in intrinsic tone is multifactorial but likely to be related to the increased circulating levels of vasodilatory substances, adrenergic receptor desensitization and uncoupling from second messenger mechanisms, and the release of cytokines during cardiopulmonary bypass $(6,32)$ that are capable of increasing expression of iNOS (34).

While increased blood flow is generally considered to be a beneficial response, maintenance of organ perfusion could be compromised by concomitant systemic hypotension, necessitating vasopressor drugs. This may result in a poor distribution of organ perfusion. Interestingly, while alpha-adrenergic and PKC-mediated microvascular responses are reduced in some vascular beds after CPB, the response to phenylephrine (an alpha-adrenergic agonist) is actually increased in the mesenteric microcirculation
(25), increasing the probability of mesenteric ischemia when vasopressor drugs are administered after CPB in order to maintain peripheral blood pressure. Thus, changes in both vasomotor tone and vascular permeability are regulated by NOS and COX. Changes in the expression and activities of these enzymes have a major impact on the recovery of patients after cardiovascular surgery, especially those subjected to extracorporeal circulation.

\section{Prevention of microvascular injury}

The use of systemic cooling and the administration of heparin (both of which decrease complement activation), utilization of blood-containing cardioplegic solutions $(8,52,53)$ and other modifications have a beneficial effect on endothelium-dependent relaxation, myogenic contraction and responses to adrenergic agonists, and other indices of vascular health during ischemic arrest. However, a clinical benefit of blood cardioplegia or of the addition of metabolic enhancers to a cardioplegic solution has been difficult to demonstrate under non-ischemic conditions $(54,55)$. The mechanism of the positive effect of blood is uncertain but may be due to its potent inhibitory effects on oxygen-derived free radical generation, improved oxygenation of tissues (thereby decreasing the amount of vascular ischemia), buffering capacity of histidine and other blood proteins or preservation of morphological integrity of the endothelium $(6,8)$. The addition of blood or magnesium to the cardioplegic solution prevents the depolarization and intracellular calcium accumulation during ischemic arrest, most likely by limiting calcium entry to the cytosol from the sarcoplasmic reticulum and extracellular space (56), and by limiting the derangement in responses mediated by the endothelium and those acting directly through the vascular smooth muscle (57). In addition, the use of continuous warm blood cardioplegia has 
been shown to better preserve coronary endothelium-dependent relaxation (53), although other studies have failed to demonstrate an improved effect over standard intermittent, cold blood cardioplegia (58). A key to this disparity between experimental and clinical effects may be related to species variations, differences in experimental and clinical conditions, and a negligible importance of each individual factor in the overall outcome of patients undergoing CPB. It is intuitive that the injury to vascular function, including activity of eNOS and predominance of the COX-1 isoform, may be prevented by limiting the factors that initiate the changes, namely, hypoxia, ischemia, or exposure to cytokines and activated leukocytes. Antiproteases such as aprotinin, in addition to decreasing blood loss after cardiopulmonary bypass, may be useful in reducing postoperative systemic inflammation (59). Finally, ischemic preconditioning may be useful in limiting vascular injury, since it has been reported to maintain endothelium-dependent relaxation and $B$-adrenergic regulation $(37,60)$.

\section{Clinical implications}

Reduction of endothelium-dependent relaxation and other changes in vasomotor regulation following cardioplegia may predispose to coronary constriction or spasm and alter the normal regulation of myocardial perfusion in the postoperative period. Recent work demonstrating an increased expression of COX-2 and increased contractile response of coronary arterioles to serotonin suggests that the administration of anti-platelet drugs such as aspirin improves short-term coronary bypass graft patency not only by preventing platelet aggregation and thrombus formation, but perhaps also by improving graft blood flow by preventing reductions in myocardial perfusion and changes in vasomotor regulation.

Inhibition of factors suspected in causing systemic inflammation has been attempted with corticosteroids to block the effects of inflammatory cytokines and expression of iNOS, COX-2, and other inflammatory enzymes. PMN activation has also been inhibited in some studies, but in general the results of these efforts have been disappointing. Inhibition of neutrophil infiltration with a monoclonal antibody to $\mathrm{C} 5 \mathrm{a}$ has resulted in improved endothelial-dependent relaxation, but without functional benefits in myocardial, pulmonary, or mesenteric recovery. However, these experiments only assessed the short-term effects of impaired neutrophil adhesion and sequestration, and long-term affects were not examined. Of considerable interest is the observation that many of the clinical manifestations observed after cardiac surgery were ascribed to CPB. Yet many of these manifestations such as systemic hypotension, cognitive dysfunction, postoperative atrial fibrillation and increased vascular permeability are observed even during "off pump" coronary artery bypass grafting, or "OP CAB", in which cardiopulmonary bypass is not utilized. Nevertheless, increasing the understanding of vascular changes during cardiac surgery and developing methods to reduce microvascular injury to the heart, brain and other organs through the use of specific tyrosine kinase and guanylate cyclase inhibitors that regulate permeability, or selective inhibitors or modulators of iNOS or COX-2 will certainly be a challenge in future investigations.

\section{References}

1. Buxton AE, Hirshfeld J r J W, Untereker WJ , Goldberg S, Harken AH, Stephenson LW \& Edie RN (1982). Perioperative coronary arterial spasm: long-term follow- up. American J ournal of Cardiology, 50: 444-451.

2. Lockerman ZS, Rose DM, Cunningham $\mathrm{J} r$ J N \& Lichstein E (1986). Postoperative
ST-segment elevation in coronary artery bypass surgery. Chest, 89: 647-651.

3. Skarvan K, Graedel E, Hasse J, Stulz P \& Pfisterer M (1984). Coronary artery 
spasms after coronary artery bypass surgery. Anesthesiology, 61: 323-327.

4. Wernovsky G, Wypij D, J onas RA, Mayer J r J E, Hanley FL, Hickey PR, Walsh AZ, Chang AC, Castaneda AR, Newburger J W \& Wessel DL (1995). Postoperative course and hemodynamic profile after the arterial switch operation in neonates and infants. A comparison of low-flow cardiopulmonary bypass and circulatory arrest. Circulation, 92: 2226-2235.

5. Sinclair DG, Haslam PL, Quinlan GJ , Pepper J R \& Evans TW (1995). The effect of cardiopulmonary bypass on intestinal and pulmonary endothelial permeability [see comments]. Chest, 108: 718-724.

6. Sellke FW, Boyle J r EM \& Verrier ED (1996). Endothelial cell injury in cardiovascular surgery: the pathophysiology of vasomotor dysfunction. Annals of Thoracic Surgery, 62: 1222-1228.

7. Sellke FW, Shafique T, Schoen FJ \& Weintraub RM (1993). Impaired endothelium-dependent coronary microvascular relaxation after cold potassium cardioplegia and reperfusion. J ournal of Thoracic and Cardiovascular Surgery, 105: 52-58.

8. Sellke FW, Shafique T, J ohnson RG, Dai $\mathrm{HB}$, Banitt PF, Schoen FJ \& Weintraub RM (1993). Blood and albumin cardioplegia preserve endothelium-dependent microvascular responses [see comments]. Annals of Thoracic Surgery, 55: 977-985.

9. Cartier R, Pellerin M, Hollmann $C \&$ Pelletier LC (1993). Effects of pressure and duration of hyperkalemic infusions on endothelial function. Annals of Thoracic Surgery, 55: 700-705.

10. Mankad PS, Chester AH \& Yacoub MH (1991). Role of potassium concentration in cardioplegic solutions in mediating endothelial damage. Annals of Thoracic Surgery, 51: 89-93.

11. Busse RLA \& Pohl U (1992). Role of Membrane Potential in the Synthesis and Release of EDRF. Endothelial Regulation of Vasomotor Tone. Marcel Dekker, New York.

12. He GW \& Yang CQ (1996). Hyperkalemia alters endothelium-dependent relaxation through non-nitric oxide and noncyclooxygenase pathway: a mechanism for coronary dysfunction due to cardioplegia. Annals of Thoracic Surgery, 61: 13941399.

13. Cavallo MJ, Dorman BH, Spinale FG \& Roy RC (1995). Myocyte contractile responsiveness after hypothermic, hyperkalemic cardioplegic arrest. Disparity between exogenous calcium and beta-adrenergic stimulation. Anesthesiology, 82:
926-939.

14. Meldrum DR, Cleveland J r J C, Sheridan BC, Rowland RT, Banerjee A \& Harken AH (1996). Cardiac surgical implications of calcium dyshomeostasis in the heart. Annals of Thoracic Surgery, 61: 12731280.

15. Engelman DT, Watanabe $M$, Engelman RM, Rousou J A, Flack 3rd J E, Deaton DW $\&$ Das DK (1995). Constitutive nitric oxide release is impaired after ischemia and reperfusion. J ournal of Thoracic and Cardiovascular Surgery, 110: 1047-1053.

16. Kukreja RC \& Hess ML (1992). The oxygen free radical system: from equations through membrane-protein interactions to cardiovascular injury and protection. Cardiovascular Research, 26: 641-655.

17. Stahl GL, Reenstra WR \& Frendl G (1995). Complement-mediated loss of endothelium-dependent relaxation of porcine coronary arteries. Role of the terminal membrane attack complex. Circulation Research, 76: 575-583.

18. Friedman $M$, Wang SY, Stahl GL, J ohnson RG \& Sellke FW (1995). Altered beta-adrenergic and cholinergic pulmonary vascular responses after total cardiopulmonary bypass. J ournal of Applied Physiology, 79: 1998-2006.

19. Beckman J S, Beckman TW, Chen J, Marshall PA \& Freeman BA (1990). Apparent hydroxyl radical production by peroxynitrite: implications for endothelial injury from nitric oxide and superoxide. Proceedings of the National Academy of Sciences, USA, 87: 1620-1624.

20. Sellke FW, Shafique T, Ely DL \& Weintraub RM (1993). Coronary endothelial injury after cardiopulmonary bypass and ischemic cardioplegia is mediated by oxygen-derived free radicals. Circulation, 88: II-395-II-400

21. Tofukuji M, Stahl GL, Agah A, Metais C, Simons M \& Sellke FW (1998). Anti-C5a monoclonal antibody reduces cardiopulmonary bypass and cardioplegia-induced coronary endothelial dysfunction. J ournal of Thoracic and Cardiovascular Surgery, 116: 1060-1068.

22. Yuan Y, Granger HJ , Zawieja D, DeFily DV $\&$ Chilian WM (1993). Histamine increases venular permeability via a phospholipase C-NO synthase-guanylate cyclase cascade. American J ournal of Physiology, 264: H1734-H1739.

23. Dreyer WJ , Michael LH, West MS, Smith $\mathrm{CW}$, Rothlein R, Rossen RD, Anderson DC \& Entman ML (1991). Neutrophil accumulation in ischemic canine myocardium. Insights into time course, distribu- tion, and mechanism of localization during early reperfusion. Circulation, 84: 400411.

24. Kawata H, Aoki M, Hickey PR \& Mayer J r J E (1992). Effect of antibody to leukocyte adhesion molecule CD18 on recovery of neonatal lamb hearts after 2 hours of cold ischemia. Circulation, 86: II-364-II-370.

25. Sellke FW, Tofukuji M, Stahl GL, Tomita M \& Fink MP (1998). Effect of C5a inhibition on mesenteric dysfunction after cardiopulmonary bypass. Shock, 9: 42 (Abstract).

26. Kawata H, Sawatari K \& Mayer J J JE (1992). Evidence for the role of neutrophils in reperfusion injury after cold cardioplegic ischemia in neonatal lambs. J ournal of Thoracic and Cardiovascular Surgery, 103: 908-917.

27. Mulligan MS, Polley MJ, Bayer RJ , Nunn MF, Paulson J C \& Ward PA (1992). Neutrophil-dependent acute lung injury. Requirement for P-selectin (GMP-140). J ournal of Clinical Investigation, 90: 16001607.

28. Vakeva AP, Agah A, Rollins SA, Matis LA Li L \& Stahl GL (1998). Myocardial infarction and apoptosis after myocardial ischemia and reperfusion: role of the terminal complement components and inhibition by anti-C5 therapy. Circulation, 97: 2259-2267.

29. Friedman M, Wang SY, Sellke FW, Cohn WE, Weintraub RM \& J ohnson RG (1996). Neutrophil adhesion blockade with NPC 15669 decreases pulmonary injury after total cardiopulmonary bypass. J ournal of Thoracic and Cardiovascular Surgery, 111: 460-468.

30. Butler J, Chong GL, Baigrie RJ, Pillai R, Westaby S \& Rocker GM (1992). Cytokine responses to cardiopulmonary bypass with membrane and bubble oxygenation. Annals of Thoracic Surgery, 53: 833-838.

31. Dauber IM, Parsons PE, Welsh CH, Giclas PC, Whitman GJ , Wheeler GS, Horwitz LD \& Weil J V (1993). Peripheral bypassinduced pulmonary and coronary vascular injury. Association with increased levels of tumor necrosis factor. Circulation, 88: 726-735.

32. Downing SW \& Edmunds J r LH (1992). Release of vasoactive substances during cardiopulmonary bypass [see comments]. Annals of Thoracic Surgery, 54: 12361243

33. Wan S, LeClerc J L \& Vincent J L (1997). Cytokine responses to cardiopulmonary bypass: lessons learned from cardiac transplantation. Annals of Thoracic Surgery, 63: 269-276. 
34. de Vera ME, Shapiro RA, Nussler AK, Mudgett J S, Simmons RL, Morris J r SM, Billiar TR \& Geller DA (1996). Transcriptional regulation of human inducible nitric oxide synthase (NOS2) gene by cytokines: initial analysis of the human NOS2 promoter. Proceedings of the National Academy of Sciences, USA, 93: 1054-1059.

35. Tofukuji M, Metais C, Li J, Franklin A, Simons M \& Sellke FW (1998). Myocardial VEGF expression after cardiopulmonary bypass and cardioplegia. Circulation, 98: II-242-II-246.

36. Sellke FW, Wang SY, Stamler A, Lopez JJ, Li J \& Simons M (1996). Enhanced microvascular relaxations to VEGF and bFGF in chronically ischemic porcine myocardium. American J ournal of Physiology, 271: H713-H720.

37. Tofukuji M, Metais C, Li J , Hariawala MD, Franklin A, Vassileva $C$, Simons $M$ \& Sellke FW (1998). Effects of ischemic preconditioning on myocardial perfusion, function, and microvascular regulation. Circulation, 98: II-197-II-204.

38. Chenoweth DE, Cooper SW, Hugli TE, Stewart RW, Blackstone EH \& Kirklin J W (1981). Complement activation during cardiopulmonary bypass: evidence for generation of $\mathrm{C} 3 \mathrm{a}$ and $\mathrm{C} 5 \mathrm{a}$ anaphylatoxins. New England J ournal of Medicine, 304: 497-503.

39. Pinckard RN, Olson MS, Giclas PC, Terry R, Boyer J T \& O'Rourke RA (1975). Consumption of classical complement components by heart subcellular membranes in vitro and in patients after acute myocardial infarction. J ournal of Clinical Investigation, 56: 740-750.

40. Stamler A, Wang SY, Li J, Thurer RL, Schoen FJ \& Sellke FW (1996). Moderate hypothermia reduces cardiopulmonary bypass-induced impairment of cerebrovascular responses to platelet products. Annals of Thoracic Surgery, 62: 191-198.

41. Adler S, Baker PJ, J ohnson RJ, Ochi RF, Pritzl P \& Couser WG (1986). Complement membrane attack complex stimulates production of reactive oxygen metabolites by cultured rat mesangial cells. J ournal of Clinical Investigation, 77: 762767.

42. Edens RE, Linhardt RJ , Bell CS \& Weiler J M (1994). Heparin and derivatized hepa- rin inhibit zymosan and cobra venom factor activation of complement in serum. Immunopharmacology, 27: 145-153.

43. Moore J r FD, Warner KG, Assousa S, Valeri CR \& Khuri SF (1988). The effects of complement activation during cardiopulmonary bypass. Attenuation by hypothermia, heparin, and hemodilution. Annals of Surgery, 208: 95-103.

44. Metais C, Li J Y, Li J, Simons $M \&$ \& Sellke FW (1999). Serotonin-induced coronary contraction increases after blood cardioplegia-reperfusion: role of COX-2 expression. Circulation (in press).

45. Parenti A, Morbidelli L, Cui XL, Douglas J G, Hood J D, Granger HJ , Ledda F \& Ziche M (1998). Nitric oxide is an upstream signal of vascular endothelial growth factorinduced extracellular signal-regulated kinase1/2 activation in postcapillary endothelium. J ournal of Biological Chemistry, 273: 4220-4226.

46. Needleman P, Turk J, J akschik BA, Morrison AR \& Lefkowith JB (1986). Arachidonic acid metabolism. Annual Review of Biochemistry, 55: 69-102.

47. Hoffman RA, Zhang G, Nussler NC, Gleixner SL, Ford HR, Simmons RL \& Watkins SC (1997). Constitutive expression of inducible nitric oxide synthase in the mouse ileal mucosa. American J ournal of Physiology, 272: G383-G392.

48. Wang $S Y$, Friedman $M$, J ohnson RG, Zeind AJ \& Sellke FW (1995). Adenosine triphosphate-sensitive $\mathrm{K}+$ channels mediate postcardioplegia coronary hyperemia. J ournal of Thoracic and Cardiovascular Surgery, 110: 1073-1082.

49. Wang SY, Friedman $M$, Franklin $A \&$ Sellke FW (1995). Myogenic reactivity of coronary resistance arteries after cardiopulmonary bypass and hyperkalemic cardioplegia. Circulation, 92: 1590-1596.

50. Wang SY, Stamler A, Li J , J ohnson RG \& Sellke FW (1997). Decreased myogenic reactivity in skeletal muscle arterioles after hypothermic cardiopulmonary bypass. J ournal of Surgical Research, 69: 40-44.

51. Wang SY, Friedman M, J ohnson RG, Weintraub RM \& Sellke FW (1994). Adrenergic regulation of coronary microcirculation after extracorporeal circulation and crystalloid cardioplegia. American J ournal of Physiology, 267: H2462-H2470.
52. Wang SY, Stamler A, Tofukuji M, Deuson TE \& Sellke FW (1997). Effects of blood and crystalloid cardioplegia on adrenergic and myogenic vascular mechanisms. Annals of Thoracic Surgery, 63: 41-49.

53. Murphy CO, Pan C, Gott J P \& Guyton RA (1995). Microvascular reactivity after crystalloid, cold blood, and warm blood cardioplegic arrest [see comments]. Annals of Thoracic Surgery, 60: 1021-1027.

54. Shapira N, Kirsh M, J ochim K \& Behrendt DM (1980). Comparison of the effect of blood cardioplegia to crystalloid cardioplegia on myocardial contractility in man. J ournal of Thoracic and Cardiovascular Surgery, 80: 647-655.

55. Shanewise JS, Kosinski AS, Coto JA \& J ones EL (1998). Prospective, randomized trial comparing blood and oxygenated crystalloid cardioplegia in reoperative coronary artery bypass grafting. J ournal of Thoracic and Cardiovascular Surgery, 115: 1166-1171.

56. Matsuda N, Tofukuji M, Morgan KG \& Sellke FW (1999). Coronary microvascular protection with magnesium: Effects on intracellular calcium and vascular function. American J ournal of Physiology, 276: $\mathrm{H} 1124-\mathrm{H} 1130$.

57. Tofukuji M, Stamler A, Li J, Franklin A, Wang SY, Hariawala MD \& Sellke FW (1997). Effects of magnesium cardioplegia on regulation of the porcine coronary circulation. J ournal of Surgical Research, 69: 233-239.

58. Tofukuji M, Stamler A, Li J , Hariawala MD Franklin A \& Sellke FW (1997). Comparative effects of continuous warm blood and intermittent cold blood cardioplegia on coronary reactivity. Annals of Thoracic Surgery, 64: 1360-1367.

59. Hill GE, Alonso A, Spurzem J R, Stammers AH \& Robbins RA (1995). Aprotinin and methylprednisolone equally blunt cardiopulmonary bypass-induced inflammation in humans. J ournal of Thoracic and Cardiovascular Surgery, 110: 1658-1662.

60. DeFily DV \& Chilian WM (1993). Preconditioning protects coronary arteriolar endothelium from ischemia-reperfusion injury. American J ournal of Physiology, 265: H700-H706. 